\title{
The adrenal gland microenvironment in health, disease and during regeneration
}

\author{
Waldemar Kanczkowski, ${ }^{1}$ Mariko Sue, ${ }^{1}$ Stefan R. Bornstein ${ }^{1,2}$ \\ ${ }^{1}$ Department of Internal Medicine III, Technische Universität Dresden, Dresden, Germany, ${ }^{2}$ Department of Endocrinology \\ and Diabetes, King's College London, London, UK
}

\begin{abstract}
The adrenal gland is a key component of the stress system in the human body. Multiple direct and paracrine interactions between different cell types and their progenitors take place within the adrenal gland microenvironment. These unique interactions are supported by high vascularization and the adrenal cortex extracellular matrix. Alterations in the adrenal gland microenvironment are known to influence the progression of several pathological conditions, such as obesity and sepsis, and to be influenced by these disorders. For example, it has been suggested that activation of immune-adrenal crosstalk during sepsis induces elevated adrenal glucocorticoid levels, whereas crosstalk between adrenocortical cells and sonic hedgehog responsive stem cells was found to contribute to the increased size of the adrenal cortex during obesity. By contrast to sepsis, where activation of adrenal glucocorticoid production has protective effects, chronic exposure to high levels of glucocorticoids induces adverse effects, typically manifested in patients with Cushing syndrome, such as increased body weight, dyslipidemia, glucose intolerance, and hypertension. Therefore, a better understanding of factors involved in the regulation of the adrenal gland microenvironment is crucial. This review highlights bidirectional interactions occurring between the adrenal gland microenvironment and systemic responses during obesity and sepsis. Furthermore, it presents and discusses recent advancements and challenges in attempts to restore or regenerate adrenal gland function, including the use of oxygenated immune-isolating devices.
\end{abstract}

Key words: Adrenal insufficiency, ACTH, Cell transplantation, Hypothalamic-pituitary-adrenal axis, Immune-adrenal crosstalk, Obesity, Sepsis

\section{INTRODUCTION}

The adrenal gland is a key component of the body's

\footnotetext{
Address for correspondence:

Waldemar Kanczkowski, Department of Internal Medicine III,

Fetscherstrasse 74, 01307 Dresden, Technische Universität

Dresden, Dresden, Germany;

E-mail: waldemar.kanczkowski@uniklinikum-dresden.de

Received: 16-07-2017, Accepted: 20-07-2017
}

stress system which is composed of the hypothalamicpituitary-adrenal (HPA) axis and the sympatheticadrenal medullary system (SAM). ${ }^{1}$ It integrates two embryonically distinct endocrine systems within one organ capsule, the steroid hormone-producing cortex and the catecholamine-producing medulla. Adrenal cortex function is mostly regulated by the adrenocorticotropic hormone (ACTH), produced 
in the pituitary gland, whereas the adrenal medulla releases high levels of catecholamines in response to the activated sympathetic nervous system (SNS). ${ }^{2,3}$ During stress, these hormones induce various protective changes which ultimately contribute to restoration of body homeostasis. In particular, both glucocorticoids (GCs) and catecholamines (CAs) are known to acutely increase plasma glucose levels, to promote elevated cardiac output, to maintain high blood pressure, and to suppress inflammation. ${ }^{2,4,5}$ Activation of another key adrenal hormone, aldosterone, is required for maintenance of homeostasis. In particular, as part of the renin-angiotensin system, aldosterone is involved in regulation of plasma sodium $(\mathrm{Na}+)$ and extracellular potassium $(\mathrm{K}+)$ levels, thereby controlling arterial blood pressure. ${ }^{6}$

Glucocorticoid hormones, acting on all nucleated cells in the body, play an important role not only in regulation of homeostasis but also in the pathogenesis of different diseases. It is therefore of utmost importance to gain a deeper insight into the mechanisms regulating adrenal hormone production. Both adrenal gland hyperactivation and insufficiency can be life-threatening. In particular, patients with Cushing syndrome, induced by chronic hypersecretion of glucocorticoids, or those suffering from Conn syndrome, due to hyperaldosteronism, have an increased risk of developing metabolic syndrome, ${ }^{7,8}$ depression,,${ }^{9,10}$ osteoporosis $^{11}$ and/or cardiovascular diseases. ${ }^{12,13}$ Over the past few years, adrenal gland insufficiency has become a growing phenomenon. Patients with congenital adrenal hyperplasia or Addison Disease develop adrenal gland insufficiency which condition requires daily hormone supplementation. Furthermore, it predisposes affected patients to increased risk of mortality due to sepsis and to developing adrenal crisis, a condition requiring emergency treatment. ${ }^{14}$

The adrenal gland has astonishing regenerative capacity and ability to adapt to various physiological or pathological conditions. ${ }^{15,16}$ It should be noted that an extensive vascular network supports a paracrine interaction between the different cell types within the adrenal gland and their progenitors, together forming a unique microenvironment. ${ }^{17,18}$ These intraadrenal interactions are known to regulate adrenal gland function during physiological and pathophysiological conditions. ${ }^{19}$
Since complex cellular and paracrine interactions occurring within the adrenal gland have been described in detail in numerous review articles, ${ }^{18-20}$ this review will highlight the connection between alterations in adrenal microenvironment function and the development of various diseases. As depicted schematically in Figure 1, this review article will also describe the impact of sepsis and obesity on adrenal gland adaptation, function, and damage. Finally, it will also provide a brief overview of some novel cellular and therapeutic approaches designed to restore adrenal gland function, which will furnish a deeper understanding of the adrenal microenvironment.

\section{THE ADRENAL GLAND MICROENVIRONMENT}

The adrenal gland combines two endocrine cellular systems of diverse embryogenic progeny within a common organ capsule, namely, the cortex and the medulla. Taking place within these two environmental niches is an interplay between various cells, including adrenocortical and chromaffin cells, their progenitors, neuronal cells, immune cells, endothelial cells, and glia cells..$^{18,21-23}$ All these cells are known to influence each other's function, either directly or in a paracrine way, through secretion of various biologically active products, including steroid hormones, catecholamines, cytokines, neurotransmitters, and neuropeptides. The latter interactions are facilitated by the high vascularization of the adrenal organ and co-expression of various receptors for these substances in most of the cells present in the adrenal gland microenvironment. ${ }^{18}$

During non-stress conditions, adrenal glucocorticoids are secreted in circadian and ultradian cycles, reaching the highest concentration in plasma at the onset of the daily activity phase. ${ }^{24}$ Rhythmicity of daily GC pulses are tightly controlled by the coordinated action of a central master circadian clock, in the suprachiasmatic nucleus of the hypothalamus (SCN), and peripheral clock machinery, located in the adrenal gland, including canonical clock protein BMAL1. ${ }^{25-27}$ While SCN controls the pulsatile secretion of two main regulators of adrenal steroidogenesis, namely, the corticotrophin-releasing hormone (CRH) and $\mathrm{ACTH}$, production and secretion of adrenomedullary catecholamines is regulated by the sympathetic nervous system and splenic nerves. ${ }^{28,29}$ 
Ample evidence supports the presence of bidirectional interactions between the adrenal cortex and the medulla. ${ }^{18} \mathrm{GCs}$ were found to enhance synthesis of CAs both in vitro ${ }^{30}$ and in vivo. ${ }^{31}$ This stimulatory effect was attributed to increased expression of phenylethanolamine N-methyltransferase (PNMT), which gene encodes for an enzyme that catalyzes the synthesis of epinephrine from norepinephrine. A key involvement of the cortex in the regulation of PNMT gene expression, and thus basal and stressinduced epinephrine production, was demonstrated in studies using mice deficient in either steroidogenic factor-1 (SF-1), glucocorticoid receptor (GR) or the corticotrophin-releasing hormone type 1 receptor (CRH1R). ${ }^{31-33}$ Accordingly, patients with congenital adrenal hyperplasia (CAH) and Addison's disease showed reduced catecholamine biosynthesis. ${ }^{34-36}$
Similarly, intact function of the adrenal medulla was found to be involved in regulation of adrenocortical hormone synthesis. It has been demonstrated that co-culture of bovine adrenocortical cells with chromaffin cells resulted in a 10 -fold increase in basal glucocorticoid secretion ${ }^{37}$ through a mechanism involving increased expression of the steroidogenic acute regulatory protein (StAR). ${ }^{18,37,38}$ In line with these findings, deletion of the tyrosine hydroxylase $(\mathrm{TH})$ gene in experimental animals revealed marked alterations in the ultrastructure of adrenocortical cells and reduced corticosterone levels. ${ }^{39}$

The adrenal cortex is characterized by a high density of endothelial cells which lie in close proximity to steroid-producing cells. ${ }^{40}$ Consequently, both adrenal hormones and endothelial cell-derived products were shown to influence the function of the adrenal vas-

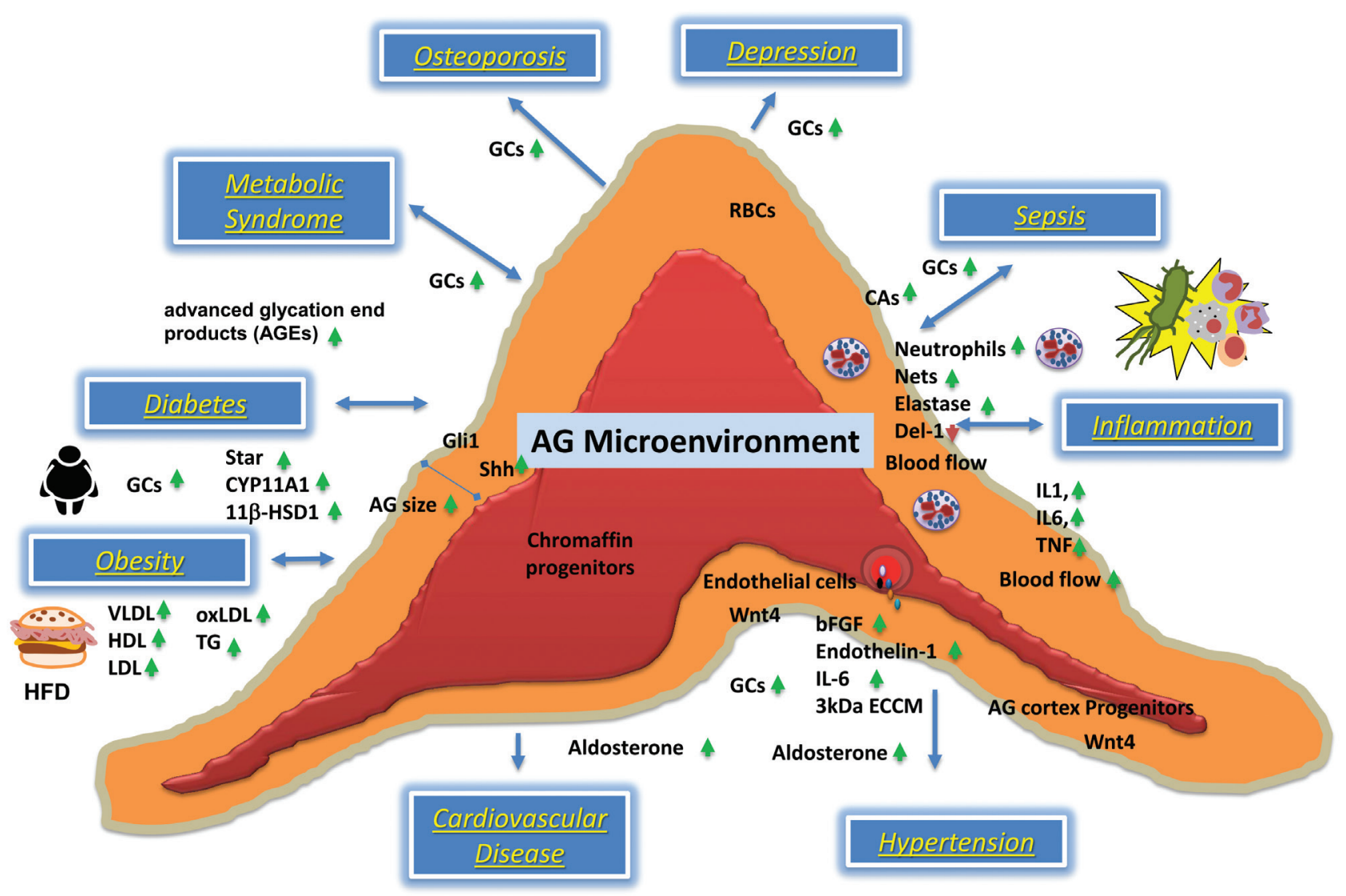

Figure 1. Bidirectional interactions between the adrenal gland microenvironment and systemic diseases. Chronic hypersecretion of glucocorticoids (GCs) and catecholamines (CAs) exert various systemic actions which are implicated in pathogenesis of many diseases. In turn, many disorders, such as e.g. obesity, have been shown to increase adrenal gland hormone production and expression of key steroidogenic enzymes including steroidogenic acute regulatory protein (StAR). The green arrow denotes an increased secretion or stimulatory action, whereas the red arrow denotes downregulation. 
culature and steroid-producing cells, respectively. ${ }^{18}$ For example, an increased production of aldosterone and cortisol was observed when human adrenocortical cells were incubated with endothelial cell conditioned media (ECCM). ${ }^{41}$ Since ECCM is a cocktail of cellderived factors, including endothelin-1, angiotensin-2 (AII), IL-6, and other as yet unidentified proteins, the exact mechanism of ECCM action remains unknown. Some studies reported that the stimulatory effect of ECCM on basal and ACTH-induced glucocorticoid production may involve endothelin-1 and nitric oxide (NO)-mediated activation of cyclic adenosine monophosphate (cAMP), but not protein kinase A (PKA)-dependent pathways. ${ }^{41}$ Other studies suggested involvement of a to date unknown protein with a molecular mass of around $3 \mathrm{kDa}$, isolated from ECCM, with the ability to increase aldosterone levels through the protein kinase C (PKC) pathway. ${ }^{42}$ Recently, a stimulatory action of basic fibroblast growth factor (bFGF) on $\beta$-catenin activity in adrenocortical cells was implicated in ECCM action. ${ }^{43}$ The adrenal gland microenvironment is rich in both glucocorticoids and catecholamines, hormones which influence the function of adrenal vascular endothelial cells. Indeed, high levels of adrenal steroids may promote and sustain production of developmental endothelial locus- 1 (Del-1), a protein that is selectively expressed in immune privileged organs and was demonstrated to act as a gatekeeper of adrenal gland inflammation. ${ }^{44}$

It has become evident that the immune and endocrine systems interact with each other at various levels and that this interaction is crucially involved in the regulation of adrenal gland function during normal and stress conditions. ${ }^{3}$ This immune-endocrine crosstalk involves direct cellular interactions occurring between adrenal and immune cells, as well as bidirectional action of steroid hormones, catecholamines, interleukins, and various vasoactive or proteolytic enzymes. ${ }^{18}$ In addition, activation of toll-like receptor signaling in hematopoietic and liver cells was found to be involved in adrenal activation during endotoxemia. ${ }^{18,45}$ During non-stress conditions, various immune cells reside in both the adrenal cortex and the medulla, including tissue macrophages, dendritic cells, mast cells, and lymphocytes. ${ }^{46-49}$ These cells stay in close cell-cell contact with adrenocortical, chromaffin, and endothelial cells, ${ }^{47,49}$ enabling them to exert bi-directional effects on other cell types. Immune cells play an important role in the regulation of adrenal homeostasis by sensing pathogens, removing apoptotic cells, and promoting tissue remodeling through e.g. secretion of growth factors. ${ }^{20,50}$ Furthermore, immune cells can regulate adrenal steroidogenesis through secretion of various cytokines, e.g. interleukins (IL)-1 and IL-6, ${ }^{51,52}$ and directly by cell-cell contact. For example, coincubation of $\mathrm{T}$ cells with primary cultures of human adrenocortical cells resulted in increased secretion of dehydroepiandrosterone (DHEA) and cortisol. ${ }^{49}$

A large number of studies demonstrate the immunomodulatory effects of adrenal hormones. For instance, a microarray analysis performed on dexamethasone-treated peripheral blood mononuclear cells (PBMC) obtained from healthy donors revealed that glucocorticoids might exert both inflammatory and anti-inflammatory actions. In resting PBMC cells, dexamethasone induced expression of various inflammatory genes, such as chemokines, cytokines, complement family members, and toll-like receptors. However, dexamethasone inhibited expression of these genes when cells were pre-treated with bacterial LPS. ${ }^{5}$ These effects are also evident in vivo. For example, chronic deficiency of adrenal hormones was recently shown to be associated with impaired natural killer cell function, which was linked to increased mortality risk ${ }^{53}$ On the other hand, an excess of glucocorticoids, which is typically manifested in patients with sepsis, contributes to immune paralysis, e.g. by promoting massive apoptosis of T cells in the thymus. ${ }^{54}$ Due to the high expression of adrenergic receptors (ARs) by a variety of immune cells, catecholamines are also known to exert numerous immunomodulatory effects. In particular, activation of $\beta 2$-adrenergic receptors by catecholamines was found to promote IL-10 secretion while simultaneously decreasing production of pro-inflammatory TNF alpha in LPStreated macrophages. ${ }^{55}$ Additionally, a differential effect of epinephrine stimulation on cytokine production in circulating neutrophils and monocytes was reported. In fact, epinephrine was found to induce dose-dependently IL-8 production in unstimulated cells, but at the same time it suppressed IL- $1 \beta$, IL-8, and monocyte chemotactic protein (MCP)-1 secretion in cells stimulated with LPS. ${ }^{56}$ 


\section{ROLE OF THE ADRENAL GLAND MICROENVIRONMENT IN VARIOUS DISEASES}

\section{In Systemic Inflammation and Sepsis}

Sepsis is one of the extreme examples of severe, sustained physical stress and is characterized by abnormal host response to infection, resulting in systemic inflammation and dysregulation of metabolism that frequently culminates in life-threatening multiple organ dysfunction. ${ }^{57} \mathrm{~A}$ fast adrenal response is critical to survive this adverse condition. ${ }^{58,59}$ Elevation of both catecholamines and glucocorticoids is crucial to prevent circulation collapse, to mobilize energy supplies, and to control initial overt inflammation. Although of vital importance for survival, regulation of adrenal gland function particularly in the later phase of sepsis, is still not fully understood. In many patients with sepsis, low ACTH levels are diagnosed despite normal or elevated cortisol levels in plasma. Multiple factors have been proposed as being involved in this process. ${ }^{60}$ These include reduced metabolism of glucocorticoids, ${ }^{61}$ intraadrenal cytokines,${ }^{62}$ increased blood flow, ${ }^{63}$ and adrenal size. ${ }^{64}$

During sepsis, the adrenal glands are heavily infiltrated by circulating immune cells. ${ }^{65,66}$ Once inside, many of these immune cells will secrete high levels of proinflammatory mediators, e.g. IL- $1 \beta$ or IL- 6 , these cytokines stimulating adrenal hormone production. ${ }^{67}$ For example, injection of IL-1 $\beta$ in hypophysectomized rats was reported to enhance corticosterone production, ${ }^{68}$ e.g. through activation of IL-1R expressed by adrenocortical or immune cells or by activation of the intraadrenal ACTH system. ${ }^{62}$ Furthermore, neutralization of TNF- $\alpha$ and IL- 6 cytokines by blocking antibodies or IL- $1 \beta$ or in IL- 6 deficiency was found to be associated with significantly lower glucocorticoid levels after LPS administration. ${ }^{69,70}$ In addition, major involvement was observed of intact TLRexpression and -signaling during LPS-induced adrenal hormone production. ${ }^{71-73}$ In sepsis, bacteria and their cell wall components are known to simultaneously activate toll-like receptors, which are expressed by most cells within the adrenal microenvironment, including myeloid, endothelial, adrenocortical, and medullary cells. ${ }^{74-76}$ Recently, mice deficient in a key TLR adaptor molecule, myeloid differentiation gene 88 (MyD88), in hematopoietic or adrenocortical cells were used to dissect TLR-dependent responses in the adrenal microenvironment. In this study, a key role of hematopoietic and liver TLR signaling in LPSinduced HPA activation was demonstrated. ${ }^{73}$ However, intact MyD88 expression in endothelial cells of the blood brain barrier was also found to contribute to glucocorticoid stimulation after LPS administration. ${ }^{77}$

Increased size of the adrenal glands during sepsis was found to correlate positively with patients' survival rate. ${ }^{64}$ One of the factors potentially involved in this finding could be increased adrenal steroidogenesis resulting from hyperplasia of adrenocortical cells and enhanced blood flow. ${ }^{63}$ In fact, injection of either angiotensin II or ACTH simultaneously increases both adrenal steroidogenesis and adrenal blood flow in experimental animals. In the latter case, activation of the splanchnic nerve, vasoactive intestinal peptide (VIP) ${ }^{78,79}$ cytochromes $450,{ }^{80}$ and vasoactive substances released from granules of mast cells ${ }^{81}$ were found to be involved.

Chronic exposure of adrenal cells to IL-1 $\beta$ and TNF $\alpha$ cytokines, neutrophil-derived reactive oxygen species (ROS), and proteolytic enzymes found in neutrophil-extracellular traps (NET) may lead to their damage. ${ }^{82}$ This in turn can contribute to adrenal exhaustion and is characterized by decreased adrenal steroidogenesis and blunted corticosterone response to ACTH stimulation. ${ }^{83,84}$ In fact, mortality of mice subjected to CLP-induced polymicrobial sepsis was correlated with increased occurrence of hemorrhages, apoptosis of cortical and chromaffin cells, and reduced response to exogenous ACTH injection. ${ }^{66} \mathrm{~A}$ postmortem study found a positive correlation between the length of stay in intensive care units (ICUs) and exhaustion of the adrenal gland. In particular, the adrenal glands of patients with the longest stay in ICUs contained the lowest cholesterol content and reduced expression of key steroidogenic enzymes as compared to short-term stay patients. ${ }^{85}$

In addition to suppressed function of adrenocortical cells in severe sepsis, an increasing number of studies suggest that the function of chromaffin cells is also compromised. For example, increased apoptosis of chromaffin cells mediated by $\mathrm{C} 5 \mathrm{a}$ anaphylatoxin was noted in mice with polymicrobial sepsis. ${ }^{86}$ Furthermore, it has been reported that in vivo administration of LPS 
resulted in reduced excitability and neuropeptide $\mathrm{Y}$ release from adrenal chromaffin cells via TLR4- and nuclear factor- $\kappa \mathrm{B}$-dependent pathways. ${ }^{71}$

\section{In Obesity and the Metabolic Syndrome}

Obesity, defined as a body mass index (BMI, the weight in kilograms divided by the square of the height in meters) above $30 \mathrm{~kg} / \mathrm{m}^{2}$, has become one of the most important public health problems not only in Western countries but also worldwide, it is being estimated to affect more than 107 million children and 600 million adults round the globe with steadily increasing prevalence. ${ }^{87}$ Currently it is a major risk factor for the development of diabetes, cardiovascular diseases ${ }^{88}$ non-alcoholic steatohepatitis, liver failure, and some cancers. ${ }^{89}$

Obesity is associated with alterations of adrenal gland function. Obese people as well as experimental animals, e.g. ob/ob mice or Zucker (fa/fa) rats, tend to have elevated levels of glucocorticoids and aldosterone in plasma.${ }^{90}$ Experimental studies have reported that the elevation of adrenal hormone levels found in these mice was associated with hyperactivity of the HPA axis, enlargement of the adrenal gland cortex, loss of leptin signaling, and increased conversion of 11-dehydrocorticosterone to corticosterone in peripheral tissues..$^{91-93}$ Loss of leptin signaling was also recently verified in another mouse model of obesity and type 2 diabetes, namely $\mathrm{db} / \mathrm{db}$ mice, along with an additional increase in plasma 11-deoxycorticosterone and progesterone, which are precursors of aldosterone and corticosterone. Interestingly, elevated ratios of aldosterone and corticosterone to progesterone in these mice indicated that the increase in progesterone levels could be only partially responsible for the elevation in steroid production. ${ }^{94}$ Leptin was shown to directly inhibit the secretion of adrenal hormones in primary cultures of bovine adrenocortical cells, $, 95,96$ which suggests that loss of leptin signaling may contribute to increased hormone levels. By contrast, suppressed plasma leptin levels were found in patients with primary aldosteronism, which suppression was resolved shortly after adrenalectomy. ${ }^{97}$ One of the mechanisms potentially involved in increased aldosterone production in obese individuals and thereby contributing to loss of leptin signaling is the mineralocorticoid stimulatory action of adipocyte secretory products. Indeed, adipocyte-conditioned medium obtained from primary cultures of human adipocytes was found to stimulate aldosterone secretion and to upregulate expression of steroidogenic enzymes in human adrenocortical cells. ${ }^{98}$

In contrast to adipocyte-conditioned medium, plasma from obese people contains high levels of well-defined factors, such as triglycerides, fatty acids, and low- (LDL), very low- (VLDL) or high- (HDL) density lipoproteins. These in turn are known to stimulate adrenal steroidogenesis in vitro and in vivo. ${ }^{99-101}$ Specifically, during stress conditions LDL and HDL lipoprotein-mediated delivery of cholesterol from the liver is required to sustain adrenal hormone production. ${ }^{100}$ In fact, mice deficient in HDL-cholesterol receptor scavenger receptor B1 (SRB1) have decreased steroidogenesis and an increased mortality rate during endotoxemia. ${ }^{102}$ Interestingly, some cholesterol-free lipoproteins such as VLDL were found to increase aldosterone production and expression of genes encoding for steroidogenic acute regulatory protein (StaR) and aldosterone synthase (CYP11B2) in adrenocortical cells, independently of this steroid precursor. ${ }^{103,104}$ A recent study demonstrated an involvement of the PLC/IP3/PKC signaling pathway in VLDL-induced aldosterone production. ${ }^{104,105}$

Patients with liver cirrhosis who have impaired lipoprotein-dependent delivery of cholesterol are at risk of developing adrenal insufficiency. ${ }^{106}$ In line with these observations, individuals deficient in the LDL receptor or those carrying inactivating mutations in genes encoding for SRB1 demonstrate a much lower cortisol response to the ACTH test. ${ }^{107,108}$ Interestingly, a recent study suggests that maternal lipids could potentially reprogram offspring's HPA axis reactivity, as elevated levels of TG, HDL, and total cholesterol through pregnancy was associated with increased cortisol reactivity in children. ${ }^{109}$

Adrenal gland function and structure undergoes dramatic changes during obesity. In a recent study, a high-fat diet (HFD) obesity model was used to evaluate these changes. Mice fed a HFD had increased body and adrenal weight, hyperplasia of the adrenal cortex, and increased secretion of corticosterone, aldosterone, and their precursors without affecting ACTH levels. ${ }^{110}$ Furthermore, elevated expression 
of the main steroidogenic enzymes, including StAR, cholesterol side-chain cleavage enzyme (Cyp11A1), 11-beta-hydroxylase (Cyp11B1), and steroid 21-hydroxylase $(\mathrm{Cyp} 21 \mathrm{OH})$ was additionally observed. By tracking the fate of a glioma-associated oncogene (Gli)-1 positive progenitor cell population, cells known to differentiate into adrenocortical cells in response to increased sonic hedgehog (Shh) levels, ${ }^{111-113}$ a rapid decrease in the number of these cells in the capsule was seen to occur after HFD. This suggests that both stem cell mobility and Shh activation may be involved in the increase of adrenal cortex size. ${ }^{110}$

The sympathoadrenal system (SAS) is composed of the adrenal medulla and the sympathetic nervous system which secrete epinephrine and norepinephrine, respectively. Activation of SAS is strongly implicated in the regulation of intermediary metabolism and the pathophysiology of obesity. ${ }^{114,115}$ Despite the existing conflicting data regarding adrenomedullary function during obesity, ${ }^{116,117}$ the results of a recent study demonstrated impaired adrenal secretion and storage of epinephrine under both fasting and feeding conditions. ${ }^{118}$

As evidenced in patients with Cushing syndrome, increased adrenal hormone production contributes to the obesity phenotype and its comorbidities. ${ }^{119}$ As for the mechanisms, elevated cortisol levels are known to promote differentiation of preadipocytes to adipocytes and to promote visceral obesity. Furthermore, GCs inhibit glucose uptake by peripheral tissues and stimulate gluconeogenesis in the liver, ${ }^{120}$ thereby contributing to insulin resistance and the development of cardiovascular diseases. ${ }^{121}$ When GCs were continuously administrated for four consecutive weeks into adult mice, they promoted an increase in body weight, an elevation in plasma leptin, insulin, and triglyceride levels, and reduced mobility. ${ }^{122}$ Interestingly, when glucocorticoids were administered in adolescent mice, blunted growth rate, induction of glucose clearance, and decreased bone density was observed. ${ }^{123}$ These experimental models clearly demonstrated the ability of prolonged corticosterone to recapitulate symptoms typically found in adult Cushing syndrome in men.

As summarized in Table 1, both sepsis and obesity influence the adrenal adaptation process leading to increased adrenal size and enhanced production of adrenal hormones. However, many septic patients, unlike obese individuals, will ultimately develop adrenal insufficiency and/or irreversible damage, requiring a life-long hormonal supplementation.

\section{THERAPEUTIC APPROACHES TO RESTORE ADRENAL GLAND FUNCTION}

Adrenal insufficiency (AI) is a rare but life-threatening disorder that requires constant hormone supplementation. Among many causes of AI, infections with certain bacteria and viruses play a key role. More specifically, suppressed function of the adrenal glands is diagnosed in patients with meningococcal meningitis, tuberculosis or adenoviral-induced adrenalitis. ${ }^{124}$ Impaired adrenal gland function may also develop due to genetic factors, e.g. in patients with congenital adrenal hyperplasia $(\mathrm{CAH})$. In these patients, suppressed cortisol and aldosterone production with androgen excess may develop as a result of several autosomal recessive diseases caused by mutations in key enzymes involved in adrenal hormone production. ${ }^{125}$ It has been estimated that 21-hydroxylase deficiency $(21 \mathrm{OH})$ accounts for more than $95 \%$ of cases of patients with CAH. ${ }^{126}$ Other important causes of adrenal dysfunction are sepsis-induced adrenal hemorrhages, medication-related causes, ${ }^{58}$ and autoimmune-mediated adrenal destruction. ${ }^{124,127}$ In addition, the modern lifestyle, certain drugs or posttraumatic syndrome can increase the risk for AI. ${ }^{128}$

Lifelong supplementation with hydrocortisone as a form of glucocorticoid replacement and fludrocortisone, used for mineralocorticoid replacement in the case of primary adrenal insufficiency, is essential in patients with $\mathrm{AI} .{ }^{14}$ However, therapeutic hormone supplementation is challenging, particularly as regards restoration of the circadian secretion pattern of adrenal glucocorticoids. It therefore poses the risk of either underdosing, leading to adrenal crisis, ${ }^{14,128}$ or overdosing, which can eventually contribute to development of osteoporosis, impaired glucose tolerance or obesity.

Considering these drawbacks related to adrenal hormone supplementation, several alternative therapeutic approaches have been proposed and tested. ${ }^{129}$ These include auto- and allotransplantations of the adrenal glands, ${ }^{130}$ adenoviral-associated virus (AAV)-mediated gene targeting, ${ }^{131,132}$ and either allo- or xenotransplan- 
Table 1. Adrenal gland (mal-)adaptation and its systemic impact during sepsis, obesity and regeneration. Adrenal gland function and structure is influenced by obesity and sepsis. Advances and challenges in regeneration or restoration of adrenal gland function.

\begin{tabular}{|c|c|c|}
\hline SEPSIS & OBESITY & REGENERATION \\
\hline Adrenal Gland (Mal-) Adaptation & Adrenal Gland (Mal-) Adaptation & Advances \\
\hline $\begin{array}{l}\text { Increased production of CAs } \\
\text { and GCs }\end{array}$ & Adrenal hyperplasia & $\begin{array}{l}\text { Increased survival of transplants with } \\
\text { decellularized ECM }\end{array}$ \\
\hline $\begin{array}{l}\text { Increased adrenal gland size } \\
\text { and blood flow }\end{array}$ & $\begin{array}{l}\text { Increased expression of steroidogenic } \\
\text { enzymes. Enhanced secretion of GCs } \\
\text { and aldosterone }\end{array}$ & $\begin{array}{l}\text { Transplantation of mixed cultures } \\
\text { of adrenal cells, including capsular } \\
\text { progenitors, improves aldosterone } \\
\text { secretion }\end{array}$ \\
\hline $\begin{array}{l}\text { Chronic exposure to cytokines and } \\
\text { neutrophil-derived anti-microbial } \\
\text { agents (NETs, ROS, Enzymes) }\end{array}$ & $\begin{array}{l}\text { Decreased storage and secretion of } \\
\text { epinephrine. Decreased adrenal } \\
\text { medullary responsiveness }\end{array}$ & $\begin{array}{l}\text { Reprogramming of own patients stem } \\
\text { cells by Sf1 overexpression }\end{array}$ \\
\hline $\begin{array}{l}\text { Adrenal exhaustion:_decreased cholesterol } \\
\text { content, expression of key steroidogenic } \\
\text { enzymes and GC response to ACTH }\end{array}$ & HPA-axis dysregulation & $\begin{array}{l}\text { Use of devices with semipermeable } \\
\text { membranes for immune protection }\end{array}$ \\
\hline Systemic Response to Adrenal Hormones & Systemic Response to Adrenal Hormones & Challenges \\
\hline $\begin{array}{l}\text { Protection against cardiovascular collapse, } \\
\text { overt inflammation and mobilization of } \\
\text { glucose }\end{array}$ & $\begin{array}{l}\text { Visceral obesity, glucose intolerance, } \\
\text { hypertension, dyslipidaemia, } \\
\text { cardiovascular diseases }\end{array}$ & $\begin{array}{l}\text { Low aldosterone and too high } \\
\text { testosterone levels }\end{array}$ \\
\hline \multirow[t]{4}{*}{$\begin{array}{l}\text { Induction of immune paralysis and increase } \\
\text { in risk of secondary infections }\end{array}$} & $\begin{array}{l}\text { Elevation in TG, cholesterol, VLDL } \\
\text { and LDL }\end{array}$ & Lack of circadian secretion of GCs \\
\hline & $\begin{array}{l}\text { Differentiation of pre-adipocytes } \\
\text { to adipocytes }\end{array}$ & $\begin{array}{l}\text { Too low GCs levels to provide protein } \\
\text { during extensive stress }\end{array}$ \\
\hline & Alteration of SAS activity & Immune rejection \\
\hline & GCs-output from Adipocytes (11ß-HSD1) & \\
\hline
\end{tabular}

tation of adrenocortical cells, ${ }^{133-139}$ or various stem cells reprogrammed into steroidogenic-like cells. ${ }^{140-142}$ Apart from allotransplantation of a whole human adrenal with its intact microenvironment, all the other experiments were performed in animals, preferentially using rodent models. ${ }^{129}$ Usually in these experiments adrenocortical cells were either transplanted directly under the kidney capsule or into the adrenal glands as single cell suspensions, or were incorporated inside various 3D scaffoldings or devices, such as polycarbonate cylinders, ${ }^{143}$ collagen sponges, ${ }^{139}$ alginate slabs or oxygenated immunoisolating devices. ${ }^{144}$

In many of these approaches, the transplanted adrenocortical cells managed to survive in vivo and to restore adrenal function in animals that underwent bilateral adrenalectomy. ${ }^{135,139,143}$ By contrast to adrenocortical cell transplantations, the majority of the studies using reprogrammed stem cells were performed only in vitro, hence the protective abilities of these adrenocortical-like cells are not known. Another important aspect is whether the amount of steroids produced by these transplanted cells can sufficiently protect the animals during stress conditions. Interestingly, in one of the very few studies that addressed this important issue, despite restoration of glucocorticoid levels to levels very similar to those found in control mice with intact adrenals, addition of another stress factor in the form of laparotomy resulted in 100\% mortality. Modulation of the experimental protocol with removal of the second adrenal gland 1 week after cell transplantation demonstrated a $42 \%$ survival rate within the first 14-days after exposure. ${ }^{139}$

Better understanding of the adrenal gland microenvironment should greatly improve the functional efficiency of adrenal transplants. As in many of these approaches only a single clonal population of adrenocortical cells from the glucocorticoid-producing zone was used, few reports demonstrated successful restoration of aldosterone production, as e.g. in one study using primary cultures of bovine cells, ${ }^{143}$ or in 
another with transplantation of mixed populations of zona fasciculata and glomerulosa cells. ${ }^{145}$ In both of these studies, an improved outcome could have been achieved by adding adrenal stem cell populations, which normally reside in the capsular and subscapular region of the gland. ${ }^{17,146}$

The adrenal gland progenitor pool is a heterogonous population of cells mostly located in the adrenal capsule and subcapsular region. ${ }^{146}$ Despite recent advances in adrenal stem cell biology, many aspects related to maintenance, self-renewal capacity, and the differentiation potential of these cells remain unknown. However, several pathways were found to play a key role in the regulation of these process, such as the mammalian wingless-type MMTV integration site (WNT) signaling pathway, hedgehog signaling, fibroblast growth factors, bone morphologic proteins, delta-like protein 1 or respondin family member 3, and proteins present within the adrenal extracellular matrix (ECM). The individual role which each of these regulatory factors plays in adrenal biology was recently summarized. ${ }^{21}$ Different populations of chromaffin stem cell/progenitor cells have been identified in adult adrenal tissues of cow ${ }^{147}$ human, ${ }^{23}$ and mouse. ${ }^{22}$ When subjected to chronic stress, these multipotent stem cells were shown to give rise to new chromaffin cells, pointing to their active participation in adrenal stress adaptation. ${ }^{148}$

Better understanding of the regulation of the function of adrenal stem cells and interaction with the adrenal microenvironment would improve our knowledge of adrenal regeneration and its adaptation to stress. For example, transplantation of adrenocortical cells in vitro into decellularized adrenal glands with intact ECM was shown to increase endocrine function and proliferation of transplanted cells. ${ }^{149}$ Adrenal ECM has a unique composition of fibronectin, laminin, and collagen IV components that have been found to improve the cultivation of adrenal cells and, in the case of collagen, also responsiveness to ACTH. ${ }^{150,151}$ Although using decellularized adrenal glands may improve the functionality of the transplant and increase the number of transplanted cells, similarly to other xenotransplantations and auto-transplantations of reprogrammed stem cells there is a major challenge, which is immune reaction of the host. ${ }^{129}$
In order to overcome this problem, an effort to create an "artificial adrenal gland" was recently attempted. In this study, a mixed population of primary bovine adrenal cells, embedded in alginate, was placed into an artificial device providing an oxygen-rich environment and simultaneous immune protection ensured by a semipermeable membrane. Upon transplantation into adrenolectomized rats, successful restoration of glucocorticoid production (cortisol) and long-term survival of the animals were observed. ${ }^{144}$ Interestingly, this device was recently used in a patient with type 1 diabetes where it successfully restored the insulin production of beta pancreatic cells. ${ }^{152}$ Unique properties of the adrenal microenvironment, in particular its vast vascularization and, as a consequence, high oxygenation together with its anti-inflammatory and immunoprotective properties, make the adrenal gland suitable for transplantation. In fact, recently an intraadrenal transplantation of rat islets was performed in diabetic mice, this approach resulting in rapid normalization of glucose levels in these animals. ${ }^{153}$

\section{SUMMARY}

Multiple direct and indirect paracrine interactions between different cell types take place simultaneously within the adrenal gland, forming a unique and flexible microenvironment. These interactions are known to regulate the function and adaptation of the adrenal gland during various pathological conditions, including obesity and sepsis. Deeper insight into the mechanisms involved in the regulation of the adrenal microenvironment should help to improve currently used therapeutic strategies for patients with adrenal insufficiency.

\section{ACKNOWLEDGMENTS}

This work was supported by grants of the Deutsche Forschungs Gemeinschaft (DFG) to WK (KA 3013/22) and SRB (BO 1141/11-2).

\section{CONFLICTS OF INTERESTS}

The authors declare that they have no conflict of interest. 


\section{REFERENCES}

1. Nicolaides NC, Kyratzi E, Lamprokostopoulou A, Chrousos GP, Charmandari E, 2015 Stress, the stress system and the role of glucocorticoids. Neuroimmunomodulation 22: 6-19.

2. Bornstein SR, Briegel J, 2003 A new role for glucocorticoids in septic shock: balancing the immune response. Am J Respir Crit Care Med 167: 485-486.

3. Chrousos GP, 1995 The hypothalamic-pituitary-adrenal axis and immune-mediated inflammation. $\mathrm{N}$ Engl J Med 332: 1351-1362.

4. Ensinger H, Geisser W, Brinkmann A, et al, 2002 Metabolic effects of norepinephrine and dobutamine in healthy volunteers. Shock 18: 495-500.

5. Galon J, Franchimont D, Hiroi N, et al, 2002 Gene profiling reveals unknown enhancing and suppressive actions of glucocorticoids on immune cells. FASEB J 16: 61-71.

6. Briet M, Schiffrin EL, 2010 Aldosterone: effects on the kidney and cardiovascular system. Nat Rev Nephrol 6: 261-273.

7. Baudrand R, Vaidya A, 2015 Cortisol dysregulation in obesity-related metabolic disorders. Curr Opin Endocrinol Diabetes Obes 22: 143-149.

8. Baudrand R, Campino C, Carvajal CA, et al, 2014 High sodium intake is associated with increased glucocorticoid production, insulin resistance and metabolic syndrome. Clin Endocrinol (Oxf) 80: 677-684.

9. Vreeburg SA, Zitman FG, van Pelt J, et al, 2010 Salivary cortisol levels in persons with and without different anxiety disorders. Psychosom Med 72: 340-347.

10. Vreeburg SA, Hoogendijk WJ, van Pelt J, et al, 2009 Major depressive disorder and hypothalamic-pituitaryadrenal axis activity: results from a large cohort study. Arch Gen Psychiatry 66: 617-626.

11. Wu VC, Chang CH, Wang CY, et al, 2017 Risk of fracture in primary aldosteronism: A population-based cohort study. J Bone Miner Res 32: 743-752.

12. Sowers JR, Whaley-Connell A, Epstein M, 2009 Narrative review: the emerging clinical implications of the role of aldosterone in the metabolic syndrome and resistant hypertension. Ann Intern Med 150: 776-783.

13. Di Dalmazi DG, Vicennati V, Garelli S, et al, 2014 Cardiovascular events and mortality in patients with adrenal incidentalomas that are either non-secreting or associated with intermediate phenotype or subclinical Cushing's syndrome: a 15-year retrospective study. Lancet Diabetes Endocrinol 2: 396-340.

14. Bornstein SR, Allolio B, Arlt W, et al, 2016 Diagnosis and treatment of primary adrenal insufficiency: An endocrine society clinical practice guideline. J Clin Endocrinol Metab 101: 364-389.

15. Tyczewska M, Rucinski M, Ziolkowska A, et al, 2014 Enucleation-induced rat adrenal gland regeneration: expression profile of selected genes involved in control of adrenocortical cell proliferation. Int $\mathrm{J}$ Endocrinol 2014: 130359.

16. Engeland WC, Gomez-Sanchez CE, Fitzgerald DA, Rogers LM, Holzwarth MA, 1996 Phenotypic changes and proliferation of adrenocortical cells during adrenal regeneration in rats. Endocr Res 22: 395-400.

17. Wood MA, Acharya A, Finco I, et al, 2013 Fetal adrenal capsular cells serve as progenitor cells for steroidogenic and stromal adrenocortical cell lineages in M. musculus. Development 140:4522-4532.

18. Ehrhart-Bornstein M, Hinson JP, Bornstein SR, Scherbaum WA, Vinson GP, 1998 Intraadrenal interactions in the regulation of adrenocortical steroidogenesis. Endocr Rev 19: 101-143.

19. Kanczkowski W, Sue M, Zacharowski K, Reincke M, Bornstein SR, 2015 The role of adrenal gland microenvironment in the HPA axis function and dysfunction during sepsis. Mol Cell Endocrinol 408: 241-248.

20. Kanczkowski W, Sue M, Bornstein SR, 2016 Adrenal gland microenvironment and its involvement in the regulation of stress-induced hormone secretion during sepsis. Front Endocrinol (Lausanne) 7: 156.

21. Lerario AM, Finco I, LaPensee C, Hammer GD, 2017 Molecular mechanisms of stem/progenitor cell maintenance in the adrenal cortex. Front Endocrinol (Lausanne) 8: 52 .

22. Rubin de Celis MF, Garcia-Martin R, Wittig D, et al, 2015 Multipotent glia-like stem cells mediate stress adaptation. Stem Cells 33: 2037-2051.

23. Santana MM, Chung KF, Vukicevic V, et al, 2012 Isolation, characterization, and differentiation of progenitor cells from human adult adrenal medulla. Stem Cells Transl Med 1: 783-791.

24. Stavreva DA, Wiench M, John S, Conway-Campbell BL, McKenna MA, Pooley JR, 2009 Ultradian hormone stimulation induces glucocorticoid receptor-mediated pulses of gene transcription. Nat Cell Biol 11: 1093-1102.

25. Son GH, Chung S, Kim K, 2011 The adrenal peripheral clock: glucocorticoid and the circadian timing system. Front Neuroendocrinol 32: 451-465.

26. Son GH, Chung S, Choe HK, et al, 2008 Adrenal peripheral clock controls the autonomous circadian rhythm of glucocorticoid by causing rhythmic steroid production. Proc Natl Acad Sci U S A 105: 20970-20975.

27. Chung S, Lee EJ, Cha HK, Kim J, Kim D, Son GH, 2017 Cooperative roles of the suprachiasmatic nucleus central clock and the adrenal clock in controlling circadian glucocorticoid rhythm. Sci Rep 7: 46404.

28. Elenkov IJ, Wilder RL, Chrousos GP, Vizi ES, 2000 The sympathetic nerve--an integrative interface between two supersystems: the brain and the immune system. Pharmacol Rev 52: 595-638.

29. Winkler H, Apps DK, Fischer-Colbrie R, 1986 The molecular function of adrenal chromaffin granules: established facts and unresolved topics. Neuroscience 18: 261-290. 
30. Wurtman RJ, 2002 Stress and the adrenocortical control of epinephrine synthesis. Metabolism 51: 11-14.

31. Yoshida-Hiroi M, Bradbury MJ, Eisenhofer G, et al, 2002 Chromaffin cell function and structure is impaired in corticotropin-releasing hormone receptor type 1-null mice. Mol Psychiatry 7: 967-974.

32. Gut P, Huber K, Lohr J, et al, 2005 Lack of an adrenal cortex in Sf1 mutant mice is compatible with the generation and differentiation of chromaffin cells. Development 132: 4611-4619.

33. Finotto S, Krieglstein K, Schober A, et al, 1999 Analysis of mice carrying targeted mutations of the glucocorticoid receptor gene argues against an essential role of glucocorticoid signalling for generating adrenal chromaffin cells. Development 126: 2935-2944.

34. Green-Golan L, Yates C, Drinkard B, et al, 2007 Patients with classic congenital adrenal hyperplasia have decreased epinephrine reserve and defective glycemic control during prolonged moderate-intensity exercise. J Clin Endocrinol Metab 92: 3019-3024.

35. Charmandari E, Eisenhofer G, Mehlinger SL, et al, 2002 Adrenomedullary function may predict phenotype and genotype in classic 21-hydroxylase deficiency. J Clin Endocrinol Metab 87: 3031-3037.

36. Bornstein SR, Breidert M, Ehrhart-Bornstein M, Kloos B, Scherbaum WA, 1995 Plasma catecholamines in patients with Addison's disease. Clin Endocrinol (Oxf) 42: $215-218$.

37. Haidan A, Bornstein SR, Glasow A, Uhlmann K, Lubke C, Ehrhart-Bornstein M, 1998 Basal steroidogenic activity of adrenocortical cells is increased 10 -fold by coculture with chromaffin cells. Endocrinology 139: 772-780.

38. Guse-Behling H, Ehrhart-Bornstein M, Bornstein SR, et al, 1992 Regulation of adrenal steroidogenesis by adrenaline: expression of cytochrome P450 genes. J Endocrinol 135: 229-237.

39. Bornstein SR, Tian H, Haidan A, et al, 2000 Deletion of tyrosine hydroxylase gene reveals functional interdependence of adrenocortical and chromaffin cell system in vivo. Proc Natl Acad Sci U S A 97: 14742-14747.

40. Kigata T, Shibata H, 2017 Anatomical variations of the arterial supply to the adrenal gland in the rat. J Vet Med Sci 79: 238-243.

41. Ansurudeen I, Willenberg HS, Kopprasch S, Krug AW, Ehrhart-Bornstein M, Bornstein SR, 2009 Endothelial factors mediate aldosterone release via PKA-independent pathways. Mol Cell Endocrinol 300: 66-70.

42. Rosolowsky LJ, Campbell WB, 1994 Endothelial cells stimulate aldosterone release from bovine adrenal zona glomerulosa cells. Am J Physiol 266: E107-E117.

43. Schwafertz C, Schinner S, Kuhn MC, et al, 2017 Endothelial cells regulate beta-catenin activity in adrenocortical cells via secretion of basic fibroblast growth factor. Mol Cell Endocrinol 441: 108-115.

44. Kanczkowski W, Chatzigeorgiou A, Grossklaus S,
Sprott D, Bornstein SR, Chavakis T, 2013 Role of the endothelial-derived endogenous anti-inflammatory factor Del-1 in inflammation-mediated adrenal gland dysfunction. Endocrinology 154: 1181-1189.

45. Bornstein SR, Ziegler CG, Krug AW, et al, 2006 The role of toll-like receptors in the immune-adrenal crosstalk. Ann N Y Acad Sci 1088: 307-318.

46. Schober A, Huber K, Fey J, Unsicker K, 1998 Distinct populations of macrophages in the adult rat adrenal gland: a subpopulation with neurotrophin-4-like immunoreactivity. Cell Tissue Res 291: 365-373.

47. Gonzalez-Hernandez JA, Bornstein SR, Ehrhart-Bornstein M, Geschwend JE, Adler G, Scherbaum WA, 1994 Macrophages within the human adrenal gland. Cell Tissue Res 278: 201-205.

48. Naccache A, Louiset E, Duparc C, et al, 2016 Temporal and spatial distribution of mast cells and steroidogenic enzymes in the human fetal adrenal. Mol Cell Endocrinol 434: 69-80.

49. Wolkersdorfer GW, Lohmann T, Marx C, et al, 1999 Lymphocytes stimulate dehydroepiandrosterone production through direct cellular contact with adrenal zona reticularis cells: a novel mechanism of immune-endocrine interaction. J Clin Endocrinol Metab 84: 4220-4227.

50. Bornstein SR, Rutkowski H, Vrezas I, 2004 Cytokines and steroidogenesis. Mol Cell Endocrinol 215: 135-141.

51. Gonzalez-Hernandez JA, Bornstein SR, Ehrhart-Bornstein M, et al, 1995 IL-1 is expressed in human adrenal gland in vivo. Possible role in a local immune-adrenal axis. Clin Exp Immunol 99: 137-141.

52. Path G, Bornstein SR, Spath-Schwalbe E, Scherbaum WA, 1996 Direct effects of interleukin-6 on human adrenal cells. Endocr Res 22: 867-873.

53. Bancos I, Hazeldine J, Chortis V, et al, 2017 Primary adrenal insufficiency is associated with impaired natural killer cell function: a potential link to increased mortality. Eur J Endocrinol 176: 471-480.

54. Arens C, Bajwa SA, Koch C, et al, 2016 Sepsis-induced long-term immune paralysis--results of a descriptive, explorative study. Crit Care 20: 93.

55. Elenkov IJ, Chrousos GP, 1999 Stress hormones, Th1/Th2 patterns, pro/anti-inflammatory cytokines and susceptibility to disease. Trends Endocrinol Metab 10: 359-368.

56. Margaryan S, Hyusyan A, Martirosyan A, Sargsian S, Manukyan G, 2017 Differential modulation of innate immune response by epinephrine and estradiol. Horm Mol Biol Clin Investig 30: [Epub ahead of print].

57. Singer M, Deutschman CS, Seymour CW, et al, 2016 The third international consensus definitions for sepsis and septic shock (sepsis-3). JAMA 315: 801-810.

58. Chan CM, Mitchell AL, Shorr AF, 2012 Etomidate is associated with mortality and adrenal insufficiency in sepsis: a meta-analysis. Crit Care Med 40: 2945-2953.

59. McKechnie K, Dean HG, Furman BL, Parratt JR, 1985 Plasma catecholamines during endotoxin infusion in conscious unrestrained rats: effects of adrenal demedullation 
and/or guanethidine treatment. Circ Shock 17: 85-94.

60. Boonen E, Bornstein SR, Van den Berghe G, 2015 New insights into the controversy of adrenal function during critical illness. Lancet Diabetes Endocrinol 3: 805-815.

61. Boonen E, Vervenne H, Meersseman P, et al, 2013 Reduced cortisol metabolism during critical illness. N Engl J Med 368: 1477-1488.

62. Mazzocchi G, Musajo FG, Malendowicz LK, Andreis PG, Nussdorfer GG, 1993 Interleukin-1 beta stimulates corticotropin-releasing hormone $(\mathrm{CRH})$ and adrenocorticotropin (ACTH) release by rat adrenal gland in vitro. Mol Cell Neurosci 4: 267-270.

63. Lang CH, Bagby GJ, Ferguson JL, Spitzer JJ, 1984 Cardiac output and redistribution of organ blood flow in hypermetabolic sepsis. Am J Physiol 246: R331-R337.

64. Jung B, Nougaret S, Chanques G, et al, 2011 The absence of adrenal gland enlargement during septic shock predicts mortality: a computed tomography study of 239 patients. Anesthesiology 115: 334-343.

65. Kanczkowski W, Chatzigeorgiou A, Samus M, et al, 2013 Characterization of the LPS-induced inflammation of the adrenal gland in mice. Mol Cell Endocrinol 371: 228-235.

66. Jennewein C, Tran N, Kanczkowski W, et al, 2016 Mortality of septic mice strongly correlates with adrenal gland inflammation. Crit Care Med 44: e190-e199.

67. Bethin KE, Vogt SK, Muglia LJ, 2000 Interleukin-6 is an essential, corticotropin-releasing hormone-independent stimulator of the adrenal axis during immune system activation. Proc Natl Acad Sci U S A 97: 9317-9322.

68. Andreis PG, Neri G, Belloni AS, Mazzocchi G, Kasprzak A, Nussdorfer GG, 1991 Interleukin-1 beta enhances corticosterone secretion by acting directly on the rat adrenal gland. Endocrinology 129: 53-57.

69. Fattori E, Cappelletti M, Costa P, et al, 1994 Defective inflammatory response in interleukin 6-deficient mice. J Exp Med 180: 1243-1250.

70. Hadid R, Spinedi E, Chautard T, Giacomini M, Gaillard RC, 1999 Role of several mediators of inflammation on the mouse hypothalamo-pituitary-adrenal axis response during acute endotoxemia. Neuroimmunomodulation 6: 336-343.

71. Lukewich MK, Lomax AE, 2013 Toll-like receptor 4 activation reduces adrenal chromaffin cell excitability through a nuclear factor-kappaB-dependent pathway. Endocrinology 154: 351-362.

72. Zacharowski K, Zacharowski PA, Koch A, et al, 2006 Toll-like receptor 4 plays a crucial role in the immuneadrenal response to systemic inflammatory response syndrome. Proc Natl Acad Sci U S A 103: 6392-6397.

73. Kanczkowski W, Alexaki VI, Tran N, et al, 2013 Hypothalamo-pituitary and immune-dependent adrenal regulation during systemic inflammation. Proc Natl Acad Sci U S A 110: 14801-14806.

74. Kanczkowski W, Zacharowski K, Wirth MP, EhrhartBornstein M, Bornstein SR, 2009 Differential expression and action of toll-like receptors in human adrenocortical cells. Mol Cell Endocrinol 300: 57-65.

75. Kawai T, Adachi O, Ogawa T, Takeda K, Akira S, 1999 Unresponsiveness of MyD88-deficient mice to endotoxin. Immunity 11: 115-122.

76. Lukewich MK, Rogers RC, Lomax AE, 2014 Divergent neuroendocrine responses to localized and systemic inflammation. Semin Immunol 26: 402-408.

77. Gosselin D, Rivest S, 2008 MyD88 signaling in brain endothelial cells is essential for the neuronal activity and glucocorticoid release during systemic inflammation. Mol Psychiatry 13: 480-497.

78. Breslow MJ, 1992 Regulation of adrenal medullary and cortical blood flow. Am J Physiol 262: H1317-H1330.

79. Engeland WC, Gann DS, 1989 Splanchnic nerve stimulation modulates steroid secretion in hypophysectomized dogs. Neuroendocrinology 50: 124-131.

80. Ansurudeen I, Kopf PG, Gauthier KM, Bornstein SR, Cowley AW Jr, Campbell WB, 2014 Aldosterone secretagogues increase adrenal blood flow in male rats. Endocrinology 155: 127-132.

81. Hinson JP, Vinson GP, Pudney J, Whitehouse BJ, 1989 Adrenal mast cells modulate vascular and secretory responses in the intact adrenal gland of the rat. J Endocrinol 121: 253-260.

82. Mikhaylova IV, Kuulasmaa T, Jaaskelainen J, Voutilainen R, 2007 Tumor necrosis factor-alpha regulates steroidogenesis, apoptosis, and cell viability in the human adrenocortical cell line NCI-H295R. Endocrinology 148: 386-392.

83. von Bruhl ML, Stark K, Steinhart A, et al, 2012 Monocytes, neutrophils, and platelets cooperate to initiate and propagate venous thrombosis in mice in vivo. $\mathrm{J}$ Exp Med 209: 819-835.

84. Tominaga T, Fukata J, Naito Y, et al, 1990 Effects of corticostatin-I on rat adrenal cells in vitro. $\mathrm{J}$ Endocrinol 125: 287-292.

85. Boonen E, Langouche L, Janssens T, et al, 2014 Impact of duration of critical illness on the adrenal glands of human intensive care patients. J Clin Endocrinol Metab 99: 4214-4222.

86. Flierl MA, Rittirsch D, Chen AJ, et al, 2008 The complement anaphylatoxin $\mathrm{C} 5 \mathrm{a}$ induces apoptosis in adrenomedullary cells during experimental sepsis. PLoS One 3: e2560.

87. GBD 2015 Obesity Collaborators, Afshin A, Forouzanfar MH, Reitsma MB, et al, 2017 Health effects of overweight and obesity in 195 countries over 25 years. N Engl J Med 377: 13-27.

88. Wormser D, Kaptoge S, Di AE, et al, 2011 Separate and combined associations of body-mass index and abdominal adiposity with cardiovascular disease: collaborative analysis of 58 prospective studies. Lancet 377: 1085-1095.

89. Global BMI MC, Di Angelantonio AE, Bhupathiraju S, Wormser D, et al, 2016 Body-mass index and all-cause 
mortality: individual-participant-data meta-analysis of 239 prospective studies in four continents. Lancet 388: 776-786.

90. Pasquali R, Vicennati V, Cacciari M, Pagotto U, 2006 The hypothalamic-pituitary-adrenal axis activity in obesity and the metabolic syndrome. Ann N Y Acad Sci 1083: 111-128.

91. McGinnis R, Walker J, Margules D, Aird F, Redei E, 1992 Dysregulation of the hypothalamus-pituitaryadrenal axis in male and female, genetically obese (ob/ob) mice. J Neuroendocrinol 4: 765-771.

92. Muller-Fielitz H, Raasch W, 2013 Angiotensin II impairs glucose utilization in obese Zucker rats by increasing HPA activity via an adrenal-dependent mechanism. Horm Metab Res 45: 173-180.

93. Naeser P, 1974 Function of the adrenal cortex in obesehyperglycemic mice (gene symbol ob). Diabetologia 10: 449-453.

94. Hofmann A, Peitzsch M, Brunssen C, et al, 2017 Elevated steroid hormone production in the $\mathrm{db} / \mathrm{db}$ mouse model of obesity and type 2 diabetes. Horm Metab Res 49: 43-49.

95. Kruse M, Bornstein SR, Uhlmann K, Paeth G, Scherbaum WA, 1998 Leptin down-regulates the steroid producing system in the adrenal. Endocr Res 24: 587-590.

96. Bornstein SR, Uhlmann K, Haidan A, Ehrhart-Bornstein M, Scherbaum WA, 1997 Evidence for a novel peripheral action of leptin as a metabolic signal to the adrenal gland: leptin inhibits cortisol release directly. Diabetes 46: 1235-1238.

97. Torpy DJ, Bornstein SR, Taylor W, Tauchnitz R, Gordon RD, 1999 Leptin levels are suppressed in primary aldosteronism. Horm Metab Res 31: 533-536.

98. Ehrhart-Bornstein M, Lamounier-Zepter V, Schraven A, et al, 2003 Human adipocytes secrete mineralocorticoid-releasing factors. Proc Natl Acad Sci U S A 100: 14211-14216.

99. Swierczynska MM, Lamounier-Zepter V, Bornstein SR, Eaton S, 2013 Lipoproteins and hedgehog signalling - possible implications for the adrenal gland function. Eur J Clin Invest 43: 1178-1183.

100. Kraemer FB, 2007 Adrenal cholesterol utilization. Mol Cell Endocrinol 265-266: 42-45.

101. Sarel I, Widmaier EP, 1995 Stimulation of steroidogenesis in cultured rat adrenocortical cells by unsaturated fatty acids. Am J Physiol 268: R1484-R1490.

102. Cai L, Ji A, de Beer FC, Tannock LR, van der Westhuyzen DR, 2008 SR-BI protects against endotoxemia in mice through its roles in glucocorticoid production and hepatic clearance. J Clin Invest 118: 364-375.

103. Saha S, Bornstein SR, Graessler J, Kopprasch S, 2012 Very-low-density lipoprotein mediates transcriptional regulation of aldosterone synthase in human adrenocortical cells through multiple signaling pathways. Cell Tissue Res 348: 71-80.
104. Tsai YY, Rainey WE, Bollag WB, 2017 Very lowdensity lipoprotein (VLDL)-induced signals mediating aldosterone production. J Endocrinol 232: R115-R129.

105. Tsai YY, Rainey WE, Johnson MH, Bollag WB, 2016 VLDL-activated cell signaling pathways that stimulate adrenal cell aldosterone production. Mol Cell Endocrinol 433: 138-146.

106. Trifan A, Chiriac S, Stanciu C, 2013 Update on adrenal insufficiency in patients with liver cirrhosis. World $\mathrm{J}$ Gastroenterol 19: 445-456.

107. Vergeer M, Korporaal SJ, Franssen R, et al, 2011 Genetic variant of the scavenger receptor BI in humans. N Engl J Med 364: 136-145.

108. Illingworth DR, Lees AM, Lees RS, 1983 Adrenal cortical function in homozygous familial hypercholesterolemia. Metabolism 32: 1045-1052.

109. Mina TH, Lahti M, Drake AJ, et al, 2017 Maternal lipids in pregnancy are associated with increased offspring cortisol reactivity in childhood. Psychoneuroendocrinology 83: 79-83.

110. Swierczynska MM, Mateska I, Peitzsch M, et al, 2015 Changes in morphology and function of adrenal cortex in mice fed a high-fat diet. Int J Obes (Lond) 39: 321-330.

111. King P, Paul A, Laufer E, 2009 Shh signaling regulates adrenocortical development and identifies progenitors of steroidogenic lineages. Proc Natl Acad Sci U S A 106: 21185-21190.

112. Pasquali R, Vicennati V, Cacciari M, Pagotto U, 2006 The hypothalamic-pituitary-adrenal axis activity in obesity and the metabolic syndrome. Ann N Y Acad Sci 1083: 111-128.

113. Wood MA, Acharya A, Finco I, et al, 2013 Fetal adrenal capsular cells serve as progenitor cells for steroidogenic and stromal adrenocortical cell lineages in $\mathrm{M}$. musculus. Development 140: 4522-4532.

114. Lambert E, Straznicky N, Sari CI, et al, 2013 Dyslipidemia is associated with sympathetic nervous activation and impaired endothelial function in young females. Am J Hypertens 26: 250-256.

115. Straznicky NE, Grima MT, Sari CI, et al, 2012 Neuroadrenergic dysfunction along the diabetes continuum: a comparative study in obese metabolic syndrome subjects. Diabetes 61: 2506-2516.

116. Esler M, Straznicky N, Eikelis N, Masuo K, Lambert G, Lambert E, 2006 Mechanisms of sympathetic activation in obesity-related hypertension. Hypertension 48: 787-796.

117. Bryde AH, Raben A, Astrup A, Christensen NJ, 1994 Plasma adrenaline concentration is lower in postobese than in never-obese women in the basal state, in response to sham-feeding and after food intake. Clin Sci (Lond) 87: 69-74.

118. Reimann M, Qin N, Gruber M, et al, 2017 Adrenal medullary dysfunction as a feature of obesity. Int $\mathrm{J}$ Obes (Lond) 41: 714-721. 
119. Thomson SP, Stump CS, Kurukulasuriya LR, Sowers JR 2007 Adrenal steroids and the metabolic syndrome. Curr Hypertens Rep 9: 512-519.

120. Qi D, Rodrigues B, 2007 Glucocorticoids produce whole body insulin resistance with changes in cardiac metabolism. Am J Physiol Endocrinol Metab 292: E654-E667.

121. Roberge C, Carpentier AC, Langlois MF, et al, 2007 Adrenocortical dysregulation as a major player in insulin resistance and onset of obesity. Am J Physiol Endocrinol Metab 293: E1465-E1478.

122. Karatsoreos IN, Bhagat SM, Bowles NP, Weil ZM, Pfaff DW, McEwen BS, 2010 Endocrine and physiological changes in response to chronic corticosterone: a potential model of the metabolic syndrome in mouse. Endocrinology 151: 2117-2127.

123. Kinlein SA, Shahanoor Z, Romeo RD, Karatsoreos IN, 2017 Chronic corticosterone treatment during adolescence has significant effects on metabolism and skeletal development in male C57BL6/N mice. Endocrinology 158: 2239-2254.

124. Brandao Neto RA, de Carvalho JF, 2014 Diagnosis and classification of Addison's disease (autoimmune adrenalitis). Autoimmun Rev 13: 408-411.

125. El-Maouche D, Arlt W, Merke DP, 2017 Congenital adrenal hyperplasia. Lancet [Epub ahead of print].

126. Speiser PW, Azziz R, Baskin LS, et al, 2010 Congenital adrenal hyperplasia due to steroid 21-hydroxylase deficiency: an Endocrine Society clinical practice guideline. J Clin Endocrinol Metab 95: 4133-4160.

127. Mitchell AL, Pearce SH, 2012 Autoimmune addison disease: pathophysiology and genetic complexity. Nat Rev Endocrinol 8: 306-316.

128. Bornstein SR, 2009 Predisposing factors for adrenal insufficiency. N Engl J Med 360: 2328-2339.

129. Ruiz-Babot G, Hadjidemetriou I, King PJ, Guasti L, 2015 New directions for the treatment of adrenal insufficiency. Front Endocrinol (Lausanne) 6: 70.

130. Grodstein E, Hardy MA, Goldstein MJ, 2010 A case of human intramuscular adrenal gland transplantation as a cure for chronic adrenal insufficiency. Am J Transplant 10: 431-433.

131. Tajima T, Okada T, Ma XM, Ramsey W, Bornstein S, Aguilera G, 1999 Restoration of adrenal steroidogenesis by adenovirus-mediated transfer of human cytochrome P450 21-hydroxylase into the adrenal gland of 21-hydroxylase-deficient mice. Gene Ther 6: 1898-1903.

132. Naiki Y, Miyado M, Horikawa R, Katsumata N, Onodera M, Pang S, 2016 Extra-adrenal induction of Cyp21a1 ameliorates systemic steroid metabolism in a mouse model of congenital adrenal hyperplasia. Endocr J 63: 897-904.

133. Cardoso CC, Bornstein SR, Hornsby PJ, 2010 Optimizing orthotopic cell transplantation in the mouse adrenal gland. Cell Transplant 19: 565-572.
134. Thomas M, Hawks CL, Hornsby PJ, 2003 Adrenocortical cell transplantation in scid mice: the role of the host animals' adrenal glands. J Steroid Biochem Mol Biol 85: 285-290.

135. Thomas M, Wang X, Hornsby PJ, 2002 Human adrenocortical cell xenotransplantation: model of cotransplantation of human adrenocortical cells and 3T3 cells in scid mice to form vascularized functional tissue and prevent adrenal insufficiency. Xenotransplantation 9: 58-67.

136. Thomas M, Yang L, Hornsby PJ, 2000 Formation of functional tissue from transplanted adrenocortical cells expressing telomerase reverse transcriptase. Nat Biotechnol 18: 39-42.

137. Thomas M, Northrup SR, Hornsby PJ, 1997 Adrenocortical tissue formed by transplantation of normal clones of bovine adrenocortical cells in scid mice replaces the essential functions of the animals' adrenal glands. Nat Med 3: 978-983.

138. Dunn JC, Chu Y, Qin HH, Zupekan T, 2009 Transplantation of adrenal cortical progenitor cells enriched by Nile red. J Surg Res 156: 317-324.

139. Zupekan T, Dunn JC 2011 Adrenocortical cell transplantation reverses a murine model of adrenal failure. J Pediatr Surg 46: 1208-1213.

140. Wei X, Peng G, Zheng S, Wu X, 2012 Differentiation of umbilical cord mesenchymal stem cells into steroidogenic cells in comparison to bone marrow mesenchymal stem cells. Cell Prolif 45: 101-110.

141. Yazawa T, Kawabe S, Inaoka Y, et al, 2011 Differentiation of mesenchymal stem cells and embryonic stem cells into steroidogenic cells using steroidogenic factor-1 and liver receptor homolog-1. Mol Cell Endocrinol 336: 127-132.

142. Yazawa T, Inanoka Y, Mizutani T, Kuribayashi M, Umezawa A, Miyamoto K, 2009 Liver receptor homolog-1 regulates the transcription of steroidogenic enzymes and induces the differentiation of mesenchymal stem cells into steroidogenic cells. Endocrinology 150: 3885-3893.

143. Thomas M, Hornsby PJ, 1999 Transplantation of primary bovine adrenocortical cells into scid mice. Mol Cell Endocrinol 153: 125-136.

144. Balyura M, Gelfgat E, Ehrhart-Bornstein M, et al, 2015 Transplantation of bovine adrenocortical cells encapsulated in alginate. Proc Natl Acad Sci U S A 112: 2527-2532.

145. Teebken OE, Scheumann GF, 2000 Differentiated corticosteroid production and regeneration after selective transplantation of cultured and noncultured adrenocortical cells in the adrenalectomized rat. Transplantation 70: 836-843.

146. Walczak EM, Hammer GD, 2015 Regulation of the adrenocortical stem cell niche: implications for disease. Nat Rev Endocrinol 11: 14-28.

147. Chung KF, Sicard F, Vukicevic V, et al, 2009 Isolation 
of neural crest derived chromaffin progenitors from adult adrenal medulla. Stem Cells 27: 2602-2613.

148. Rubin de Celis MF, Bornstein SR, AndroutsellisTheotokis A, et al, 2016 The effects of stress on brain and adrenal stem cells. Mol Psychiatry 21: 590-593.

149. Allen RA, Seltz LM, Jiang H, et al, 2010 Adrenal extracellular matrix scaffolds support adrenocortical cell proliferation and function in vitro. Tissue Eng Part A 16: 3363-3374.

150. Chamoux E, Narcy A, Lehoux JG, Gallo-Payet N, 2002 Fibronectin, laminin, and collagen IV as modulators of cell behavior during adrenal gland development in the human fetus. J Clin Endocrinol Metab 87: 1819-1828.
151. Chamoux E, Narcy A, Lehoux JG, Gallo-Payet N, 2002 Fibronectin, laminin, and collagen IV interact with ACTH and angiotensin II to dictate specific cell behavior and secretion in human fetal adrenal cells in culture. Endocr Res 28: 637-640.

152. Ludwig B, Rotem A, Schmid J, et al, 2012 Improvement of islet function in a bioartificial pancreas by enhanced oxygen supply and growth hormone releasing hormone agonist. Proc Natl Acad Sci U S A 109: 5022-5027.

153. Schubert U, Schmid J, Lehmann S, et al, 2013 Transplantation of pancreatic islets to adrenal gland is promoted by agonists of growth-hormone-releasing hormone. Proc Natl Acad Sci U S A 110: 2288-2293. 